\title{
НАУЧНЫЕ АРХИВЫ
}

УДК 911.2:556.16

DOI: https://doi.org/10.17308/geo.2021.2/3455

ISSN 1609-0683

\section{Вариация стока и его факторов ${ }^{1}$}

\author{
Н. П. Чеботарев \\ профессор, доктор технических наук \\ Воронежский государственный университет \\ Воронеж, 1949
}

\begin{abstract}
Аннотация: Редакция журнала «Вестник ВГУ. Серия: География. Геоэкология» публикует монографию Н. П. Чеботарева «Вариация стока и его факторов». Проблема, поднятая автором в середине XX века, актуальна и сегодня. Однако монография Н. П. Чеботарева стала библиографической редкостью уже сразу после выхода в свет.

Текст книги воспроизводится в авторском варианте. Для понимания важности проблемы в современных исследованиях в области гидрологии публикацию книги предваряет комментарий кандидата географических наук С. Д. Дегтярева (Вестник ВГУ. Серия: География. Геоэкология, 2018, № 3).
\end{abstract}

Ключевые слова: речной сток, вариация стока, факторы стока.

Для цитирования: Чеботарев Н.П. Вариация стока и его факторов // Вестник Воронежского государственного университета. Серия: География. Геоэкология, 2021, № 2, c. 101-103. DOI: https://doi. org/10.17308/geo.2021.2/3455

VII. ВАРИАЦИЯ ЭКСТРЕМАЛЬНОГО СТОКА

\section{А. Вариация максимального стока}

\section{1. ОБЩИЕ СВЕДЕНИЯ}

Рассмотрев достаточно подробно вариацию годовых осадков стока и испарения, а также найдя типы выражений для весеннего стока, теперь остановимся несколько на вопросе вариации экстремального стока и, в частности, максимального стока талых и ливневых вод. Определение максимальных расходов талых и ливневых вод всегда связано с обеспеченностью, с которой должен устанавливаться тот или другой расчетный расход. Поэтому вариация максимального стока и ее критерий -коэффициент вариации - должны в этом определении играть существенную роль. В литературе мы встречаемся с указаниями, что коэффициент вариации максимального стока талых вод имеет слабую зависимость его от площади бассейна (например, Соколовский Д.Л.) (17) и что он может быть определен даже непосредственно по изолиниям, построенным для $\mathrm{C}_{\mathrm{y}}$. Такое географическое интерполирование $\mathrm{C}_{\mathrm{y}}$ может иметь место в том случае, если бы значения $\mathrm{C}_{\mathrm{y}}$ зависели только от метеорологических условий и ни в коем случае от площади бассейна. Попытка проф. Д.Л. Соколовского найти зависимость между изменчивостью максимумов стока и изменчивостью максимальной толщины снежного покрова показала на недостаточную тесную связь между этими величинами. Имеются попытки разрешить эту задачу и у других авторов, но до сих пор можно считать ее неразрешенной.

\section{2. ВАРИАЦИИ МАКСИМАЛЬНОГО СТОКА} ТАЛЫХ ВОД

Коэффициент вариации максимальных расходов равен коэффициенту вариации модуля максимальных расходов. Это положение очевидно и не требует доказательств. Так как модуль максимального расхода

$$
\mathrm{M}=\frac{\mathrm{A} 1}{F^{n}}
$$

то такое же очевидное равенство будет иметь и здесь, а именно

$$
\mathrm{C}_{\mathrm{vm}}=\mathrm{C}_{\mathrm{vA}}
$$

(C) Чеботарев Н.П., 2021

Продолжение. Начало в журналах «Вестник ВГУ. Серия: География. Геоэкология» № 3 /2018 г., № 4 /2018 г., № 1 /2019 г., № 2 /2019 г., № 3 /2019 г., № 4 /2019 г., № 1 /2020 г., № 2 /2020 г., № 3 /2020 г., № 4 /2020 г. и № 1 /2021 г.

Контент доступен под лицензией Creative Commons Attribution 4.0 License. 
Но элементарный сток, или, что одно и то же, средняя интенсивность снеготаяния $\mathrm{A}_{1}$ за отрезок времени $(\tau)$, предшествующий образованию максимального расхода и в течение которого наблюдается максимальный сток, составляется из интенсивности снеготаяния а и потерь талых вод $\mathrm{p}$, т. е. A1 $=a-\rho$. Все три величины $\mathrm{A}_{1}, a$ и $p$ являются переменными на протяжении всего периода половодья. При этом ход каждой из них по отношению к ходам двух других переменных является асинхронным.

Схематически это можно представить так (рис. 12). Так как величины а и р мало зависимы друг от друга (по крайней мере на отрезке $t$ времени $\tau$ ), то с известным приближением можем написать, что

$$
\sigma_{A}^{2}=\sigma_{a}^{2}+\sigma_{p}^{2}
$$

откуда

$$
C_{y A} C_{v a} \sqrt{\left(\frac{\bar{a}}{\bar{A}}\right)^{2}+\left(\frac{\bar{p}}{\overline{\bar{A}}}\right)^{2}\left(\frac{C v p}{C v a}\right)^{2}}
$$

Обозначая отношения $\frac{\bar{a}}{\bar{A}}$ через $\bar{\eta}$ (коэффициент нормы весеннего стока), а $\frac{\bar{p}}{\mathrm{~A}}$ через $\bar{\gamma}$ (коэффициент нормы потерь) и отношение $\frac{C v p}{C v a}$ через $\delta$, получим

$$
\mathrm{C}_{v A}=C_{v a} \sqrt{\left.\overline{\eta^{2}}+\overline{(\eta}-1\right)^{2} \delta^{2}}
$$

где $\bar{\gamma}=\bar{\eta}-1$ и следовательно, упрощая, напишем, что

$$
\mathrm{C}_{v A}=\bar{\eta}^{v} C_{v a} \text {. }
$$

Максимальная интенсивность снеготаяния а зависит от целого ряда различных факторов и главными можно назвать сумму положительных температур за период снеготаяния и запас воды в снеге - $\mathrm{x}$, т.е.

$$
a=f[\Sigma(\theta+2), x]
$$

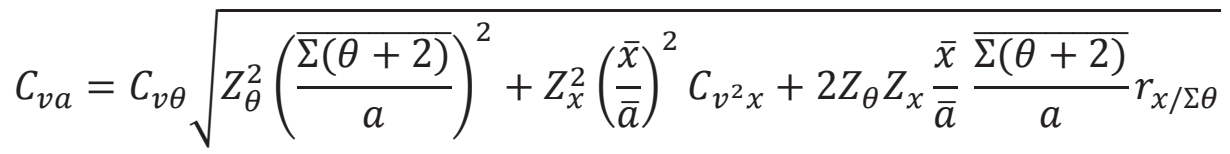
снеготаяние. написать, что

$$
a=\frac{d x}{d t}=-k x
$$
мени

$$
x=x_{\theta} e^{-k t}
$$
виде:

где $\mu>1$

$$
k=C[\Sigma(\theta+2)]
$$

$\mathrm{C}$ - некоторая постоянная

Подставив (106) в уравнение (104), получим

$$
a=-C[\Sigma(\theta+2)]^{x}
$$
соответствующих преобразований найдем

По данным Быковской стоковой станции, а также другим данным, было установлено, что интенсивность снеготаяния находится в прямой зависимости от высоты снежного покрова или от запаса воды в нем. Некоторые из гидрологов стремились объяснить это явление затяжной весной, когда возможно резкое нарастание положительных температур, однако такое объяснение не подтверждается для некоторых других затяжных весен. Сама высота снежного покрова или запас воды в нем является основным фактором интенсивности снеготаяния, так как, чем больше высота снежного покрова, тем больше остается теплоты в снежном массиве и тем интенсивнее происходит

Поэтому, исходя из сказанного, можно

Интегрируя уравнение (104) мы найдем запас воды в снежном покрове (х) в каждый момент вре-

Коэффициент пропорциональности $\mathrm{k}$ зависит от суммы положительных температур. Форма аналитического выражения зависимости на основании данных наблюдений представляется в

$\theta$ - температура воздуха за период снеготаяния

Обозначив $\frac{\partial f}{\partial x}$ через $Z_{x}$ и $\frac{\partial f}{\partial a}$ через $Z_{\text {a }}$ после

Обозначив отношение $\frac{\overline{\frac{\sum(\theta+2)}{a}}}{a}$ через $\beta_{1}$, а отношение $\frac{\bar{x}}{\bar{a}}$ через $\beta_{2}$, получим упрощенные равенства

$$
\mathrm{C}_{v a}=\beta_{1}^{m_{1}} C_{\theta}
$$

или

$$
\mathrm{C}_{v a}=\beta_{2}^{-m_{2}} C_{\gamma x}
$$

Итак, следовательно, вариация максимальных расходов зависит от вариации сумм положительных температур в период снеготаяния, от вариации запаса вод в снежном покрове и вариации потерь талых вод.
Для запаса воды в снежном покрове, так же как и для сумму температур, по аналогии с выражением для годовых высот остатков можно написать, что

$$
\mathrm{C}_{V X}=\frac{C_{V X(i)}}{F^{n}}
$$

и, следовательно, коэффициент вариации максимальных расходов

$$
C_{v Q}=\bar{\eta}^{r} \bar{\beta}_{2}^{m_{2}} \frac{C_{V X(i)}}{F^{n}}=\bar{\eta}^{r} \bar{\beta}_{1}^{m_{1}} \frac{C_{V \theta(i)}}{F^{n}} .
$$


К этому выражению можно прийти, если коэффициент вариации интенсивности снеготаяния выразить через площадь бассейна, а именно

$$
\begin{gathered}
C_{v a}=\frac{C_{v a(i)}}{F^{n}}, \\
C_{v a(i)}=\bar{\beta}_{2}^{m_{2}} \quad C_{\mathrm{Y} X(i)}=\bar{\beta}_{1}^{m_{1}} C_{V \theta(i)}
\end{gathered}
$$

Следовательно, подобно вариации годового стока участие площади бассейна здесь косвенное и как косвенный фактор площадь бассейна может входить в формулы для определения коэффициента вариации. Однако могут встречаться случаи, когда зависимость вариации от площади бассейна так же, как и для годового стока выражена слабо или вовсе отсутствует. Так, например для р. Ю. Буг мы не видим достаточной связи между $\mathrm{C}_{\mathrm{vQ}}$ и $\mathrm{F}$. Нарушения подобного вида можно объяснить следующими соображениями. Для тех бассейнов рек, для которых условия снеготаяния не являют- ся разнородными и асинхронными, несмотря на большую величину площади бассейна, указанная выше зависимость (112) должна быть нарушена. Однако не только однородность и синхронность метеорологических условий снеготаяния может являться причиной отсутствия достаточной связи, но также и величина времени пробега, которая в некоторых случаях не может измеряться только величиной площади, взятой в степени $\mathrm{n}$.

Если бассейн характеризуется условиями, вызывающими значительное увеличение или, наоборот, уменьшением времени пробега, отличающее от данной степени $\mathrm{F}^{\mathrm{n}}$, то связь может быть нарушена.

Такое нарушение может быть также и вследствие ненадежности исходных данных. Последняя особенность всецело относится к многим рекам Украины, и вряд ли данные этих рек могут служить для каких-либо, указывающих на эти закономерности, выводов.

\title{
SCIENTIFIC ARCHIVES
}

UDC 911.2:556.16

DOI: https://doi.org/10.17308/geo.2021.2/3455

ISSN 1609-0683

\section{Variation of Runoff and its Factors}

\author{
N. P. Chebotarev \\ Doctor of Sciences in Technology \\ Voronezh State University \\ Voronezh, 1949
}

\begin{abstract}
The editorial board of the journal «Bulletin of VSU. Series: Geography. Geoecology» publishes the monograph of N. P. Chebotarev «Variation of runoff and its factors». The issue raised by the author in the middle of the 20th century is still relevant today. However, the monograph of N. P. Chebotarev became a bibliographic rarity immediately after the publication.

The text of the book is reproduced in the author's version. To understand the importance of the problem in modern research in the field of hydrology, the publication of the book is preceded by a comment by S. D. Degtyarev - candidate of geographical sciences (Vestnik Voronezskogo gosudarstvennogo universiteta. Seria: Geografia. Geoekologia, 2018, no. 3).

Key words: river runoff, runoff variation, runoff factors.

For citation: Chebotarev N.P. Variation of Runoff and its Factors. Vestnik Voronezskogo gosudarstvennogo universiteta. Seria: Geografia. Geoekologia, 2021, no. 2, pp. 101-103. (In Russ.). DOI: https://doi.org/10.17308/ geo.2021.2/3455
\end{abstract}

(C) Chebotarev N.P., 2021

The content is available under Creative Commons Attribution 4.0 License.

Вестник ВГУ, Серия: География. Геоэкология, 2021, № 2, 101-103 